\title{
Склонение к совершению самоубийства / доведение до самоубийства: лингвистическая трактовка дифференциации содержания ст. 110 и ст.110.1.УК РФ
}

\author{
Г. С. Иваненко \\ Южно-Уральский государственный гуманитарно-педагогический университет \\ пр. Ленина, 69, 254080, г.Челябинск, Россия. E-mail:gala.april@mail.ru
}

\begin{abstract}
В исследовании представлено лингвистическое толкование двух статей уголовного кодекса РФ, посвященных различным видам побуждения к самоубийству: статья 110. Доведение до самоубийства (в ред. Федерального закона от $07.06 .2017 \mathrm{~N}$ 120-Ф3) и статья 110.1. Склонение к совершению самоубийства или содействие совершению самоубийства (введена Федеральным законом от 07.06.2017 N 120-Ф3. На основе изучения содержания судебных процессов рассматриваемого типа выявлена зона конфликтности, связанная с интерпретаций ключевых понятий законодательных актов. В результате сравнения языковых формулировок, использованных для характеристики деяния и средств его осуществления, устанавливается смысл, извлекаемый из текстов статей по законам языка. Во-первых, довести до самоубийства, то есть привести к лишению жизни, - обозначение самых разнообразных действий, а склонить, то есть "убедить», - действие исключительно речевое. Во-вторых, понятия «склонение» и «способствование» предполагают мирный, внешне комфортный характер вредоносного деяния, а «доведение до самоубийства», напротив, принесение страдания. Склонение и способствование (ст.110.1.) - это прежде всего интеллектуальное (философское, психологическое, речевое) преступление по формированию сознания. Это либо становление мировоззренческой картины, в которой отказ от бытия является достойным выбором, либо создание мотивации для ухода из жизни (подкуп), либо обман (пояснение законодателем и практика правоприменения отсутствует). Доведение же до самоубийства (с.110) - насильственное действие, причиняющее моральный или физический вред и тем самым снижающее ценность жизни. И, наконец, сама языковая форма слов обусловливает трактовку: “доведение до...»-обязательно результативное действие (суицид совершился или предпринята попытка), склонение - деяние, не требующее обязательного результата.
\end{abstract}

Ключевые слова: склонение к совершению самоубийства, доведение до самоубийства, лингвистическое толкование закона.

\section{Inducement to Commit Suicide / Incitement to Suicide: Linguistic Interpretation of Differentiation of the Contents of Article 110 and Article 110.1. of The Criminal Code of the Russian Federation}

\author{
G. S. Ivanenko \\ South UralState University of Humanities and Education \\ Lenin Ave., 69, 254080, Chelyabinsk, Russia.E-mail:gala.april@mail.ru
}

\begin{abstract}
This article presents a linguistic interpretation of two articles of the criminal code of the Russian Federation on different types of inducement to suicide: article 110. Bringing to suicide (in the edition of the Federal law of 07.06.2017 N 120 -FZ) and article 110.1. Inducement to commit suicide or assistance in committing suicide (introduced by the Federal law of 07.06.2017 N 120-FZ. Based on the study of the content of the judicial processes of the considered type, the conflict zone associated with the interpretation of key concepts of legislative acts is revealed. As a result of comparison of the language formulations used to characterize the act and the means of its implementation, the meaning derived from the texts of articles on the laws of language is established. First, to bring to suicide, that is, to lead to the deprivation of life, is the designation for a wide variety of actions, and to persu ade, that is, "convince", is an action exclusively verbal. Secondly, the concepts of "declination" and" promotion "imply a peaceful, apparently comfortable nature of the harmful act, and "bringing to suicide", on the contrary, bringing suffering. Inducement and promoti on (article 110.1.)- this above all intellectual (philosophical, psychological, speech) crime on formation consciousness. This is either
\end{abstract}


the formation of a worldview picture in which the rejection of being is a worthy choice, or the creation of motivation for le aving life (bribery), or deception (explanation by the legislator and the practice of law enforcement is absent). Bringing to suicide (p. 110) - a violent act that causes moral or physical harm and thereby reduces the value of life. And, finally, the linguistic form of words itself determines the interpretation: "bringing to..." is necessarily a productive action (a suicide has been committed or an attempt has been made), declension is an act that does not require a mandatory result.

Key words: inducement to commit suicide, incitement to suicide, linguistic interpretation of the law.

Один из видов толкования юридического текста - лингвистический. Со стороны юридического сообщества нередко звучат критические замечания, суть которых сводится примерно к следующему: юристы и сами владеют языком в достаточной мере, чтобы понять любое высказывания, поэтому комментарии филологов излишни. Возможно, в каких-то ситуациях действительно обращения к специалистам вызваны не столько потребностью в установлении смысла, сколько намерением заручиться дополнительным доказательным средством, содержащим научно выстроенную аргументацию, что, в общем, тоже свидетельствует о востребованности лингвистического знания, пусть не как средства установления обстоятельств, а как средства их научного обоснования [Иваненко 2006, 20018]. Но в настоящей публикации обратим внимание читателя на ту нишу, в которой, как представляется, отсутствие лингвистического комментария серьезно повлияло на юридическую практику.

1. «Виртуализация» преступлений, связанных с суицидом

Недавно по стране прокатилась волна дел, связанных с различными видами побуждения к самоубийству. Поданным Судебного департамента Верховного Суда Российской Федерации [12] количество осужденных за данное преступление составило в 2013 году - 15 осужденных, в 2014 - 8, в 2015 - 15, в 2016 - 10, в 2017 - 6, 2018 - 20. Притом побуждение к лишению жизни в век информационных технологий приобрело новые черты. Не так давно в доведении до самоубийства обвинялись люди, своими действиями или словами делающие невыносимой жизнь тех, кто по каким-то причинам от них зависел. Известны случаи самоубийства детей, не выдерживающих давления со стороны учителей или родителей, травли одноклассников; людей, находящихся в беспомощном состоянии и несущих груз постоянных попреков и унижений. Публикации на эту темудо 2017 года [Соломатина 2014; Щетинина 2016] раскрывают исключительно юридические понятия состава преступления. Общими чертами дел о доведении до самоубийства прошлого поколения были следующие признаки:

1) факт самоубийства или его попытки;

2) жертва и обвиняемый обычно знакомы лично;

3) воздействие на жертву в значительном ряде случаев не речевого характера (избиения, плохой уход), в ситуациях речевого воздействия максимально конкретно (публичное унижение, клевета, угрозы).

2. Изменение законодательства в связи спреступлениями, побуждающими к суициду

Правовой основой квалификации деяния выступала статья 110УК РФ Доведение до самоубийства. 07.06.2017 названная статья была подвергнута редакции, также введены новые статьи 110.1 Склонение к совершению самоубийства или содействие совершению самоубийства и 110.2.Организация деятельности, направленной на побуждение к совершению самоубийства Ук РФ. Законодатель расширил список деяний, приводящих к самоубийству, деяниями, потенциально способными к нему привести. И содержание этого дополнения гораздо сложнее соотносится с действительностью по сравнению с уже действующей статьей. Еще до приятия новой редакции закона высказывались замечания о предстоящих трудностях в квалификации деяний по смежным составам [Синельщиков 2017]. С момента внесения статей 110.1 и 110.2 УК РФ была вынесена череда обвинительных приговоров. Признаки этого нового поколения дел, связанных с побуждением к самоубийству:

1) факт самоубийства или его попытки не значим (согласно формулировке, оценивается наличие / отсутствие склонения к самоубийству);

2) жертва и обвиняемый не знакомы лично;

3) воздействие на жертву имеет отвлеченно-философский, психолого-программирующий характер.

Сравнение характера дел последней волны с предыдущим типом позволяет увидеть «виртуализацию» исследуемого правового и реального пространства в прямом и переносном смысле. Отношения жертвы и подозреваемого из плоскости реальных отношений объективной действительности перенеслись в плоскость интернет-коммуникации. Представляли ли оба коммуниканта в этом взаимодействии самих себя или создавали образы? Действовали они самостоятельно или реализовывали чью-то волю? И вообще были ли это они? Недавно состоялся процесс, в котором несовершеннолетняя жертва не опрашивалась судом, ее интересы представляли родители. Статус жертвы подтверждался общим эмотивным фоном письменных высказываний и выводами психолога о дисбалансе внутреннего состояния подростка. Однако какую роль в формировании этого состояния сыграли родители, какую - школа, социум? Или оно есть результат влияния чужого человека - знакомого по интернет-переписке? Все это сложные вопросы, уходящие корнями в психологию, философию, социологию. Методики установления значимых обстоятельств в делах такого рода пока, судя по характеру процессов, еще не созданы. Но необходимость их интерпретации средствами лингвистики стала очевидной. Даже юридические научные работы последнего периода на эту тему содержат выход в анализ языка [Сараева 2017; Сафонова, Скобина 2018].

Поскольку под действие ст.110.1. УК РФ попадают случаи не только свершившегося самоубийства, но и возможного, отсутствуют иные свидетельства губительного воздействия одного лица на другое, кроме речевых. «Суицидальный» эффект влияния определяется по единственному в таких случаях доказательному средству - текстам коммуникации, что обусловливает определяющую роль лингвистической и психологической экспертизы. Но особенности лингвистической экспертизы по делам такого типа не являются предметом настоящей статьи. Мы предлагаем разобраться в законодательных формулировках, интерпретация которых определяет решение суда.

3. Дифференциация: доведение до самоубийства (ст.110 УК РФ) / склонение к совершению самоубийства (ст.110.1 УК РФ)

Лингвистический комментарий, который далее прозвучит, может показаться излишним. Однако он порожден наблюдением за реальными процессами, в ходе которых содержание двух статей не дифференцировалось и семантика различа ющих их понятий не учитывалась. Против лиц, задействованных так или иначе в коммуникации на тему «суицид», выдвигались обвинения сразу по двум статьям, содержание которых смешивалось, объединялось, трактовалось через взаимные ссылки.

Процитируем части статей, раскрывающие содержание инкриминируемого действия:

УК РФ Статья 110. Доведение до самоубийства (в ред. Федерального закона от 07.06.2017 N 120-Ф3)

1. Доведение лица до самоубийства или до покушения на самоубийство путем угроз, жестокого обращения или систематического унижения человеческого достоинства потерпевшего ... 
УК РФ Статья 110.1. Склонение к совершению самоубийства или содействие совершению са моубийства (введена Федеральным законом от 07.06.2017 N 120-ФЗ

1. Склонение к совершению самоубийства путем уговоров, предложений, подкупа, обмана или иным способом при отсутствии признаков доведения до самоубийства...

2. Содействие совершению самоубийства советами, указаниями, предоставлением информации, средств или орудий совершения самоубийства либо устранением препятствий к его совершению или обещанием скрыть средства или орудия совершения самоубийства...

Сопоставление содержания инкриминируемых действий приводит к выделению ключевых дифференцирующих понятий: доведение до самоубийства / склонение к самоубийству. Применяя методику анализа семантико-грамматической конструкции [Иваненко 2017], определим семантическую структуру понятий.

Доведение до чего-либо - отвлеченное существительное с процессуальной семантикой, производное от глагола довести.

ДОВЕСТИ

ДОВЕСТЙ, -еду, -едёшь; -ёл, -ела; -еди; -едший; -едённый (-ён, -ена); -едя; совер.

1. кого (что) дочего. Ведя, доставить до какого-н. места. Д. старика до дому.

2. что до чего. Продолжить до какого-н. места, предела. Д. дорогу доморя. Д. дело до конца.

3. кого (что) до чего. Привести в какое-н. состояние, вызвать, породить в ком-чём-н. какие-н. последствия. Д. до слёз, до изнеможения.

4. кого (что). Раздражить, рассердить (прост.). Ты решил меня сегодня д.!

- Довести до сведения кого (офиц.) уведомить, известить очём-н.

| несовер. доводить, -ожу, -одишь [Ожегов, Шведова URL].

В контексте ст. 110 УК РФ реализуется значение №3: «Привести в какое-нибудь состояние, вызвать, породить в ком-чем-нибудь какие-нибудь последствия».

Склонение, как и доведение, - отвлеченное существительное с процессуальной семантикой, производное от глагола «склонить».

СКлОни́ть, -оню, -онишь и -онишь; -нённый (-ён, -ена); совер.

1. что. Нагнуть, опустить. С. ветки. С. знамёна перед могилами павших бойцов (высок.). С. голову (также перен.: 1) перед чем, утратив волю к сопротивлению, подчиниться, поддаться чему-н.; высок. С. голову перед судьбой; 2) перед кем (чем), отдать дань уважения, благодарности; высок.).

2. перен., кого (что) к чему или на что. Убедить в необходимости какого-н. поступка, решения. С. к побегу. С. на свою сторону. [Ожегов, Шведова URL].

В контексте ст. 110.1. реализуется значение №2: «Убедить в необходимости какого-нибудь поступка, решения».

Содействие - существительное с процессуальным значением, производное от глагола «содействовать».

СОДЕ́ЙСТВИЕ, -я, ср. Деятельное участие в чьих-н. делах с целью облегчить, помочь, поддержка в какой-н. деятельности. Оказать с. Товарищеское с. Комиссия содействия. [Ожегов, Шведова URL].

Определения в других словарях аналогичны приведенным. Они не устраняют необходимости поиска дополнительных характеристик для дифференциации двух действий: «привести в какое-нибудь состояние, вызвать, породить в ком-чем-нибудь какиенибудь последствия» и «убедить в необходимости какого-нибудь поступка, решения», которые в рассматриваемом случае читаются как «привести к самоубийству» и «убедить в необходимости самоубийства». Это не значит, что определения плохи или неправильны, но целевое лингвистическое исследование требует каждый раз раскрытия определенных связей и взаимоотношений между знаком и явлением, между двумя или более знаками, и эта задача пока не имеет типового решения [Иваненко 2012, 2018]. Неудивительно, что в ходе судебного разбирательства стороны выясняют вопросы:

- Разве склонить к самоубийству, то есть убедить в необходимости самоубийства, не значит довести до самоубийства, то есть привести к самоубийству?

- Можно ли привести к самоубийству, убедив в его необходимости?

- Содействие чему-либо приводит к этому чему-либо, то есть может считаться «доведением до...»?

Действительно, понятия "довести до чего-либо» и «склонить к чему-либо», «содействовать», судя по данным определениям, имеют отношения инклюзии: второе частный случай первого. Склонив к самоубийству и / или способствуя ему, можно до него довести. Эта плоскость семантического пересечения и становится основанием для автоматического включения в обвинение вслед за ст. 110.1 «Склонение к...» и ст.110 «Доведение до...». Однако при таком не подходе не учитываются следующие особенности языковой природы исследуемых понятий.

Во-первых, «привести» - глагол, связанный с самыми разнообразными действиями, а «убедить» - действие исключительно речевое.

Во-вторых, понятия «склонение» и «способствование» предполагают мирный, внешне, на этапе взаимодействия, комфортный характер вредоносного деяния, а «доведение до самоубийства», напротив, мучительный для жертвы. Принесённые преступником страдания и становятся причиной трагедии. Приведенный перечень способов совершения преступления не оставляет сомнений в том, что склонение и способствование - это прежде всего интеллектуальное (философское, психологическое, речевое) преступление по формированию сознания, а доведение до самоубийства-насильственное, причиняющее моральный или физический вред и тем самым снижающее ценность жизни для жертвы.

И, наконец, доведение - обязательно результативное действие (суицид совершился или предпринята попытка), согласно самой внутренней форме слова с приставкой до- со значением завершенного действия (доделать, дописать, добить). Склонение - деяние, не требующее обязательного результата. В существительном склонение не отражен однозначно вид производящего глагола: склонять или склонить. Денотат, обозначенный избранной субстантивной формулировкой, содержит сему фиксации процесса, но не содержит сему фиксации его результата.

Сопоставление языковых формулировок статей 110 в аспекте «доведение» и 110.1 в аспекте «склонение» УК РФ по ряду параметров представлено в таблице 1: 


\begin{tabular}{|c|c|c|}
\hline статьи & СТ. 110 УК РФ & СТ. 110.1 УК РФ \\
\hline Инкриминируемое деяние & Доведение до самоубийства & $\begin{array}{l}\text { 1) Склонение к совершению самоубийства. } \\
\text { 2) Содействие совершению самоубийства. }\end{array}$ \\
\hline $\begin{array}{l}\text { Словарное определение } \\
\text { совершаемого деяния }\end{array}$ & $\begin{array}{l}\text { Привести в какое-нибудь состояние, } \\
\text { вызвать, породить в ком-чем-нибудь } \\
\text { какие-нибудь последствия }\end{array}$ & $\begin{array}{l}\text { 1)Убедить в необходимости какого-нибудь поступка, } \\
\text { решения } \\
\text { 2)Деятельное участие в чьих-н. делах с целью } \\
\text { облегчить, помочь, поддержка в какой-н. } \\
\text { деятельности. }\end{array}$ \\
\hline Фактический результат деяния & $\begin{array}{l}\text { Самоубийство или покушение на } \\
\text { самоубийство }\end{array}$ & $\begin{array}{l}\text { Самоубийство или попытка самоубийства являются } \\
\text { не обязательными признаками, а отягчающими } \\
\text { обстоятельствами }\end{array}$ \\
\hline $\begin{array}{l}\text { Ключевое слово, определяющее } \\
\text { содержание деяния }\end{array}$ & Доведение до & $\begin{array}{l}\text { Склонение к } \\
\text { Содействие }\end{array}$ \\
\hline Общее в семантике & \multicolumn{2}{|l|}{$\begin{array}{l}\text { Подведение к действию, поступку, решению } \\
\text { Вызвать последствия }\end{array}$} \\
\hline Различное в семантике & $\begin{array}{l}\text { последствие вызвано } \\
\text { действие не только речевое } \\
\text { действие принесло страдания }\end{array}$ & $\begin{array}{l}\text { последствие не вызвано (без отягчения) } \\
\text { действие речевое } \\
\text { действие не принесло страдания }\end{array}$ \\
\hline Средства совершения деяния & $\begin{array}{l}\text { угрозы } \\
\text { жестокое обращение } \\
\text { систематическое } \\
\text { человеческого достоинства }\end{array}$ & $\begin{array}{l}\text { уговоры } \\
\text { предложения } \\
\text { подкуп } \\
\text { обман } \\
\text { или иные способы } \\
\text { (при отсутствии признаков доведения до } \\
\text { самоубийства) }\end{array}$ \\
\hline $\begin{array}{l}\text { Наказание } \\
\text { (лет лишения свободы) }\end{array}$ & $\begin{array}{l}\text { До } 5 \text { лет без отягчающих обстоятельств, } \\
\text { до } 15 \text { лет - с } \text { отягчающими } \\
\text { обстоятельствами }\end{array}$ & $\begin{array}{l}\text { До } 2 \text { лет (склонение), до } 3 \text { лет (содействие) без } \\
\text { отягчающих обстоятельств, } \\
\text { до } 15 \text { лет - с отягчающими }\end{array}$ \\
\hline
\end{tabular}

Комплексное сравнение позволяет сделать неформальный вывод: законодатель считает деяния, подпадающие под ст. 110, более тяжким по сравнению с деянием по ст. 110.1. (без отягчающих обстоятельств). В соответствии со ст.110, человека побуждают к самоубийству, причиняя физические или моральные страдания, а ст.110.1. соотноситма с событиями, при которорых страдание человеку не причинялось.

В реальности в ходе многочисленных процессов, имевших место в последнее время, указанные различия не учитываются. За одно и то же деяние лицу инкриминируется и ст. 110, и ст. 110.1. Отчасти такая нивелировка обусловлена языковыми причинами, а именно плоскостью семантического пересечения ключевых понятий, организующих смысл статей: доведение до / склонение, содействие. Представленный материал преследовал цель дать лингвистический комментарий языковым фактам, определяющим существенные аспекты трактовки рассматриваемыхзаконов.

\section{Литература}

1. Ефремова Т.Ф. Новый словарь русского языка. Толково-словообразовательный. - М., 2000. URL: https://dic.academic.ru/ (дата обращения 28.11.2019)

2. Иваненко Г.С. Язык как исток, объект и средство реализации права / Юриспруденция XXI века: горизонты развития. Очерки. под редакцией Р. А. Ромашова, Н. С. Нижник. - Санкт-Петербург, 2006. - С. 501-518.

3. Иваненко Г.С. Понятие значения, смысла, понимания, восприятия, интерпретации текста в концепции целевого лингвистического судебного исследования / Мир науки, культуры, образования. - 2012 . - № 4 (35). С. 74-78. URL:https://elibrary.ru/download/elibrary_17947346_68779275.pdf (дата обращения 28.11.2019)

4. Иваненко Г.С. Люди нашего царя (к вопросу о методике анализа семантико-грамматической конструкции в лингвистической экспертизе) / Юрислингвистика. - 2017. - №6. - с. 89-101. URL: https://elibrary.ru/download/elibrary_34877630_67541940.pdf (дата обращения 28.11.2019)

5. Иваненко Г.С. Лексикография и лингвистическая экспертиза: перспективы взаимоотношений / Юрислингвистика. 2018. - №7-8. - С.98118. URL: https://elibrary.ru/download/elibrary_36308533_92890145.pdf (дата обращения 28.11.2019)

6. Иваненко Г.С. На пересечении языка и права. Из практики производства судебных лингвистических экспертиз. М., 2018.

7. Ожегов С.И., Шведова Н.Ю. Толковый словарь русского языка. URL: https://dic.academic.ru/ (дата обращения 29.11.2019).

8. Сараева Ю.В. Доведение до самоубийства: особенности объективной стороны / Юридический вестник Самарского университета. 2017. - Т.3. - №2. - C.112-118. URL: https://cyberleninka.ru/article/n/dovedenie-do-samoubiystva-osobennosti-obektivnoy-storony (дата обращения 27.11.2019).

9. Сафонова Т.Б., Скобина Е.А. Склонение к совершению суицида и доведение до самоубийства: новелла или коллизия в уголовном праве PФ? / «Научное сообщество студентов. Междисциплинарные исследования»: сборник статей. - Новосибирск, 2018. - № 8(43). URL: https://sibac.info/archive/meghdis/8(43).pdf (дата обращения 27.11.2019)

10. Синельщиков Ю.П. Выступление 19 июля 2017 г. по поводу проекта федерального закона о внесении изменений в статью 110.1 и 110.2 УК РФ (в части усиления ответственности за склонение к совершению самоубийства). URL: http://www.sinelschikov.info/speech-item/91 (дата обращения 28.11.2019). 
11. Соломатина Е.А. Особенности расследования доведения до самоубийства несовершеннолетних: учебно-методическое пособие. M., 2014. URL: https://lawbook.online/metodika-kriminalisticheskaya/osobennosti-rassledovaniya-dovedeniya.html (дата обращения 17.04.2018).

12. Судебный Департамент при Верховном Суде PФ. URL: http://www.cdep.ru/ (дата обращения 28.11.2019).

13. Уголовный кодекс Российской Федерации от $13.06 .1996 \mathrm{~N}$ 63-Ф3 $\quad$ (ред. от 19.02.2018). URL: http://www.consultant.ru/document/cons_doc_LAW_10699/bddefeedee59e3a0cd80ee378c510bee13dabeb0/ (дата обращения 28.11.2019) 14. Федеральная служба государственной статистики. URL: http://www.gks.ru/ (дата обращения 28.11.2019).

15. Щетинина Н.В. Некоторые вопросы применения статьи 110 Уголовного кодекса Российской Федерации, предусматривающей ответственность за доведение до самоубийства / Вестник Уральского юридического университета МВД России. - Екатеринбург, 2016. URL: $\quad$ https://cyberleninka.ru/article/n/nekotorye-voprosy-primeneniya-stati-110-ugolovnogo-kodeksa-rossiyskoy-federatsi ipredusmatrivayuschey-otvetstvennost-za-dovedenie-do (Дата обращения 27.11.2019).

\section{References}

1. Efremova T. F. New dictionary of the Russian language. Expla natory-word-formation. - Moscow, 2000. URL: https://dic.academic.ru/ (accessed 28.11.2019)

2. Ivanenko G. S. Language as a source, object and means of realization of law / Jurisprudence of the XXI century: horizons of development Essays. edited by R. A. Romashov, N. S. Nizhnik. - St. Petersburg, 2006. - Pp. 501-518.

3. Ivanenko G. S. the Concept of meaning, meaning, understanding, perception, interpretation of the text in the concept of ta rget linguistic judicial research / World of science, culture, education. - 2012. - No. 4 (35). Pp. 74-78.

4. Ivanenko G. S. People are our king (to the question of the method of analysis of the semantic and grammatical structure in linguistic expertise) / Jurilinguistic. - 2017. - No. 6. pp. 89-101.

5. Ivanenko G. S. Lexicography and linguistic expertise: prospects of cooperation / Jurilinguistic. 2018. - No. 7-8. - Pp. 98-118.

6. Ivanenko G. S. at the intersection of language and law. From practice of production of judicial linguistic examinations. Moscow, 2018 (2nd edition, stereotypical) - 279s.

7. Ozhegov S. I., Shvedova N. Yu. Explanatory dictionary of the Russian language. URL: https://dic.academic.ru/ (accessed 29.11.2019).

8. Saraeva Yu. V. Bringing to suicide: features of the objective side / Legal Bulletin of Samara University. - 2017. -- T. 3. -- No. 2. - Pp. 112-118. URL: https://cyberleninka.ru/article/n/dovedenie-do-samoubiystva-osobennosti-obektivnoy-storony (appeal 27.11.2019).

9. Safonova T. B., Skobina E. A. Inducement to commit suicide and bringing to suicide: a novel or a conflict in the criminal law of the Russian Federation? / "Scientific community of students. Interdisciplinary research": collection of articles. - Novosibirsk, 2018. - No. 8 (43). URL: https://sibac.info/archive/meghdis/8(43).pdf (accessed 27.11.2019)

10. Sinelshchikov Yu. p. Speech on July 19, 2017 on the draft Federal law on amendments to article 110.1 and 110.2 of the cri minal code (in terms of strengthening responsibility for inducing suicide). URL: http://www.sinelschikov.info/speech-item/91 (accessed 28.11.2019).

11. Solomatina E. A. Features of investigation of bringing to suicide of minors: the educational and methodical manual. - M., 2014. URL: https://lawbook.online/metodika-kriminalisticheskaya/osobennosti-rassledovaniya-dovedeniya.html (accessed 17.04.2018).

12. Judicial Department at the Supreme Court of the Russian Federation / / URL: http://www.cdep.ru/ (accessed 28.11.2019).

13. Criminal code of the Russian Federation from 13.06.1996 N 63-FZ (as amended on 19.02.2018). URL:

http://www.consultant.ru/document/cons_doc_LAW_10699/bddefeedee59e3a0cd80ee378c510bee13dabeb0/ (accessed 28.11.2019)

14. Federal state statistics service. URL: http://www.gks.ru/ (accessed 28.11.2019).

15. Shchetinina N. V. Some questions of application of article 110 of the Criminal code of the Russian Federation providing responsibility for bringing to suicide / Bulletin of the Ural law University of the Ministry of internal Affairs of Russia. - Yekaterinburg, 2016. URL:

https://cyberleninka.ru/article/n/nekotorye-voprosy-primeneniya-stati-110-ugolovnogo-kodeksa-rossiyskoy-federatsii-predusmatrivayuscheyotvetstvennost-za-dovedenie-do (accessed 27.11.2019).

\section{Citation:}

Иваненко, Г.С. Склонение к совершению самоубийства / доведение до самоубийства: лингвистическая трактовка дифференциации содержания ст. 110 и ст.110.1.УК РФ. // Юрислингвистика. -2019. - 14. - С.14-18.

Ivanenko, G. S. (2019). Inducement to Commit Suicide / Incitement to Suicide: Linguistic Interpretation of Differentiation of the Contents of Article 110 and Article 110.1. of The Criminal Code of the Russian Federation. Legal Linguistics, 14, 14-18.

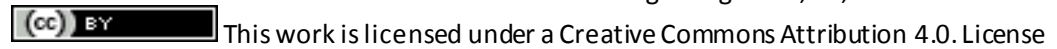

